\title{
Associations between fatty acid consumption and vascular health: evidence from the Caerphilly cohort
}

\author{
K. M. Livingstone ${ }^{1}$, J. A. Lovegrove ${ }^{2}$, D. I. Givens ${ }^{1}$ \\ ${ }^{1}$ Food Production and Quality Research Division, Faculty of Life Sciences, University of Reading, RG6 6AR, \\ ${ }^{2}$ Department of Food and Nutritional Sciences and Institute for Cardiovascular and Metabolic Research, Faculty of Life \\ Sciences, University of Reading, RG6 6AR, UK
}

Although research has indicated that the replacement of dietary saturated fatty acids (SFA) with mono- or poly-unsaturated fatty acids (MUFA or PUFA) may reduce the risk of cardiovascular disease (CVD) via effects on lipids, blood pressure and endothelial function ${ }^{(1-2)}$, evidence from long-term prospective studies on the effect of fatty acid consumption on vascular health is insufficient and inconsistent ${ }^{(3)}$.

The present analysis aimed to investigate the relationship between total fat, SFA, PUFA and an estimated MUFA intake (eMUFA) with systolic and diastolic blood pressure (SBP and DBP), pulse wave velocity (PWV), plasma insulin, glucose, triacylglycerol (TAG) and fibrinogen concentrations using data from the Caerphilly cohort. Included in this cohort were 2,512 men, aged 45-59 years at phase (P) 2, who were followed up at 5 year intervals (P 2-3 for total fat, P 2-3 for SFA, eMUFA and PUFA and P 1-2 for insulin, P 1-3 and 5 for SBP, DBP, TAG, glucose and fibrinogen and P 5 for PWV). Multiple linear regression analysis was used to investigate cross-sectional and longitudinal relationships, with adjustments for dietary and lifestyle variables.

\begin{tabular}{|c|c|c|c|c|c|c|c|c|}
\hline & \multicolumn{6}{|c|}{ Cross sectional $^{1}$} & \multirow{2}{*}{\multicolumn{2}{|c|}{$\begin{array}{c}\text { Longitudinal }^{2} \\
\text { PWV }\end{array}$}} \\
\hline & \multicolumn{2}{|c|}{ SBP } & \multicolumn{2}{|c|}{ DBP } & \multicolumn{2}{|c|}{ Glucose } & & \\
\hline & Coef & $\overline{\mathrm{SE}}$ & Coef & $\overline{\mathrm{SE}}$ & Coef & $\overline{\mathrm{SE}}$ & Coef & $\mathrm{SE}$ \\
\hline Total fat & -0.008 & 0.035 & $0.038^{*}$ & 0.019 & $0.001 * * *$ & 0.001 & -0.025 & 0.007 \\
\hline SFA & $0.121 *$ & 0.060 & $0.103^{* *}$ & 0.032 & $0.002 * * *$ & 0.001 & $0.022 *$ & 0.011 \\
\hline eMUFA & -0.080 & 0.119 & -0.021 & 0.064 & $0.004 * * *$ & 0.001 & 0.015 & 0.022 \\
\hline PUFA & $-2.513^{*}$ & 1.093 & -0.755 & 0.593 & -0.008 & 0.009 & $-0.520 * *$ & 0.198 \\
\hline SFA: total fat & $23.62 * *$ & 8.828 & $14.03 * *$ & 4.788 & 0.088 & 0.070 & $4.339 * *$ & 1.587 \\
\hline PUFA: SFA & $-2.058 *$ & 0.858 & $-1.124^{*}$ & 0.465 & $-0.015^{*}$ & 0.007 & $-0.425^{* *}$ & 0.154 \\
\hline$\% \mathrm{E}$ from SFA & 26.60 & 14.03 & $24.88 * * *$ & 7.605 & $0.359 * * *$ & 0.112 & 4.643 & 2.589 \\
\hline
\end{tabular}

PWV, pulse wave velocity; SBP; systolic blood pressure; DBP, diastolic blood pressure; 1 , association between dietary intake at P 2 with blood pressure at $\mathrm{P} 2 ; 2$, association between dietary intake at $\mathrm{P} 2$ with $\mathrm{PWV}$ at $\mathrm{P} 5$; coefficients were significantly different at $* P<0.05$, $* * P<0.01, * * * P<0.001$.

At $\mathrm{P} 2$, increasing SFA consumption was associated with higher $\mathrm{P} 2 \mathrm{SBP}(\mathrm{P}=0.043)$, DBP $(\mathrm{P}=0.002)$ and glucose concentrations $(P=0.001)$ and higher $\mathrm{PWV}$ in $\mathrm{P} \mathrm{V}(P=0.049)$. Also at $\mathrm{P} 2$, increasing PUFA consumption was associated with a lower $\mathrm{P} 2$ SBP $(P=0.022)$ and $\mathrm{P} 5 \mathrm{PWV}(P=0.009)$. This led to a lower P 2 SBP $(P=0.017)$, DBP $(P=0.016)$, glucose $(P=0.025)$ and $\mathrm{P} 5$ PWV $(P=0.006)$ with an increasing dietary P:S (PUFA:SFA) ratio. The present results suggest that consumption of SFA is associated with CVD risk, while PUFA may be related to cardio-protective markers. Importantly, as indicated by PWV, consumption of SFA and PUFA may predict future risk of CVD.

This work was supported by the Barham Benevolent Trust and the University of Reading. The authors gratefully acknowledge the Department of Social Medicine in Bristol for access to the Caerphilly archive and valuable support from Professor Peter Elwood and Janet Pickering.

1. Vafeiadou K, Weech M, Sharma V et al. (2012) Brit J Nutr 107, 303-24.

2. Hooper L, Summerbell CD, Thompson RL et al. (2011) Proc Nutr Soc 70, E222.

3. Siri-Tarino PW, Sun Q, Hu FB et al. (2010) Am J Clin Nutr 91, 535-46. 